\title{
Students' Assessments about InfoStart Internship Program, in Economic Informatics and Cybernetics
}

\author{
Adriana REVEIU, Ana Ramona BOLOGA \\ Bucharest University of Economic Studies \\ reveiua@ase.ro,ramona.bologa@ie.ase.ro
}

\begin{abstract}
This paper provides an overview about the expectations and assessment of students attending the internship program in Economic Informatics and Cybernetics, developed within InfoStart program, organized at the Faculty of Economic Informatics, Cybernetics and Statistics, from Bucharest University of Economic Studies, Romania. 397 students accomplished 3 weeks internship stage, in May 2015, within InfoStart program. In order to identify the expectations of the students from the target group, a sociological survey has been conducted at the beginning of InfoStart program. At the end of the internship program, developed within the project, the attending students fulfilled self-evaluation reports. So 397 completed self-evaluation reports have been achieved and used to set up the analysis. The students' responses reveal a very successful internship program in Economic Informatics and Cybernetics, in term of program quality, program utility, students' self-assessment behavior, and companies' employee behavior. The results reveal that three internship factors, namely: a pleasant working environment, good working infrastructure and proficient trainer, get students overall satisfaction of the internship stage.
\end{abstract}

Keywords: Internship, Students' Assessment, Students' Expectation

1 Introduction

Students' internship opportunities provide valuable authentic learning experience to engage students in solving their work problems. [2]

Scientific literature offer different approaches for the internship. Fox [3] considers internship as an opportunity to close the gap between academic learned theory and practical reality.

The relationship between academic education and internship have been widely deliberated. Internship serves the requirements of the three parties: students, academic institution and industry partners. Students and industry related companies are aware of the direct benefits of practical experiences incorporated into university curricula.

According with [5] students increasingly demand well-organized internship programs, in order to acquire professional skills. At the same time, industry seeks effective ways to train student trainees, from their organization and, to reduce uncertainty in the hiring process in later stages.

Throughout the internship period, students work collaboratively with members of the work site and develop hands-on skills to accomplish particular tasks [1].

Fox [3] asserts that a bad internship experience can just quickly turn a young person away from the industry.

In order to attract as many graduated students as possible to start their career in the Economic Informatics and Cybernetics, both the school and industry should collaborate closely to develop a well-organized quality internship program.

A quality internship program, can be developed when the parties have the answers for some questions like the following: What do students expect, prior to starting the internship program? What do students perceive, after the internship program? Which is the overall internship satisfaction level? What is the relationship between the gap of expectations and perceptions and overall satisfaction?

According to [4], people's expectation and perception have a close relationship with evaluation of quality and satisfaction levels. Expectation represents how people perceive before, the experience, and perception means how people think after the experience. The gap between perception and expectation, give 
the indication of satisfaction level after people's experience. This approach is used to evaluate InfoStart internship program.

Although a number of studies available in the scientific literature emphasize students' internship experiences, from our information it is no paper focusing on internship in Economic Informatics and Cybernetics, available for Romania.

So, the objectives of this study are: first, to identify students' expectation before, and, perception after, the internship program, and second, to identify overall internship satisfaction, and to investigate the relationship between the expectation and perception.

\section{InfoStart Internship Program Goals}

The project "InfoStart - The beginning of your career in IT" is financed by the European Social Fund, in the Operational Programme for Human Resources Development, 2007 2013, POSDRU/161/2.1/G/138408. The project aims to facilitate the insertion on the labor market, of students enrolled in the bachelor and master programs in Economic Informatics and Cybernetics, organized by Bucharest University of Economic Studies. The project organized innovative internships stages, by using ICT based support resources, within the inter partnerships diversification initiatives.

Long-term positive effects expected for InfoStart project are: decreasing the unemployment among young people - which currently is high enough, by providing relevant and practical skills for the students involved in the program. Another positive impact is providing job offers, adapted to market needs, so employers effort of selection and training of future employees will be much lower. In a third, of all, during the internship, the theoretical knowledge acquired in the academic system will be adjusted and enforced by the students, so they will be prepared more to adapt to the new job, when they will be employed.

The specific objectives of InfoStart project are:

- Increasing relevance of learning outcomes achieved in the workplace, by organizing interactive and innovative approaches, for conducting a program of internships for specializations: Economic Informatics and Cybernetics, covering the necessary skills and enabling the application of theoretical knowledge in real environment;

- Facilitate the transition from academic studies to actively life, for 400 students, through participation, in innovative programs of practical training support materials, including ICT resources;

- Developing and strengthen the existing partnership between academic environment and employers, in order to facilitate the integration of students into the labor market, by involving 10 organization / companies, to diversify the organization of traineeships;

Increased capacity to adapt to labor market by providing students' guidance and advices.

\section{Students' Expectations about InfoStart Internship Program}

During the InfoStart project, an activity aimed to identify the main expectations of the students, from the target group has been completed. In order to achieve the goal of this activity, a research survey among the target group has been fulfilled, namely the students enrolled, in the second and in the third year of bachelor and master programs, at the Faculty of Cybernetics, Statistics and Economic Informatics, from Bucharest University of Economic Studies.

For setting-up this activity, a methodology based on sociological survey has been used. In order to collect students' opinion, a questionnaire has been designed. The used questionnaire contained 22 questions, 7 of which were segmentation / socio-demographic identification questions.

Given the specific of the target group, and based on temporal and material resources available, an online solution to collect data has been used. Although only 41 fulfilled questionnaires have been received, the recorded information were used to identify the needs of the target group.

Some questions refer to the advantages expected by the students of InfoStart internship program. 
The answers provided by students from the target group about the expected benefits of the internship program are presented in figure 1 . Acquiring new practical skills, specific to the needs of Economic Informatics and Cybernetics business areas is specified, by $44 \%$ of respondents, as the main advantages of partici- pating in InfoStart internship project. Acquiring new knowledge specific for the academic domain is identified as the major benefits by $34 \%$ of respondents, and $12 \%$ of respondents indicated that the internship has an important role in training of new professionals in the professional field.

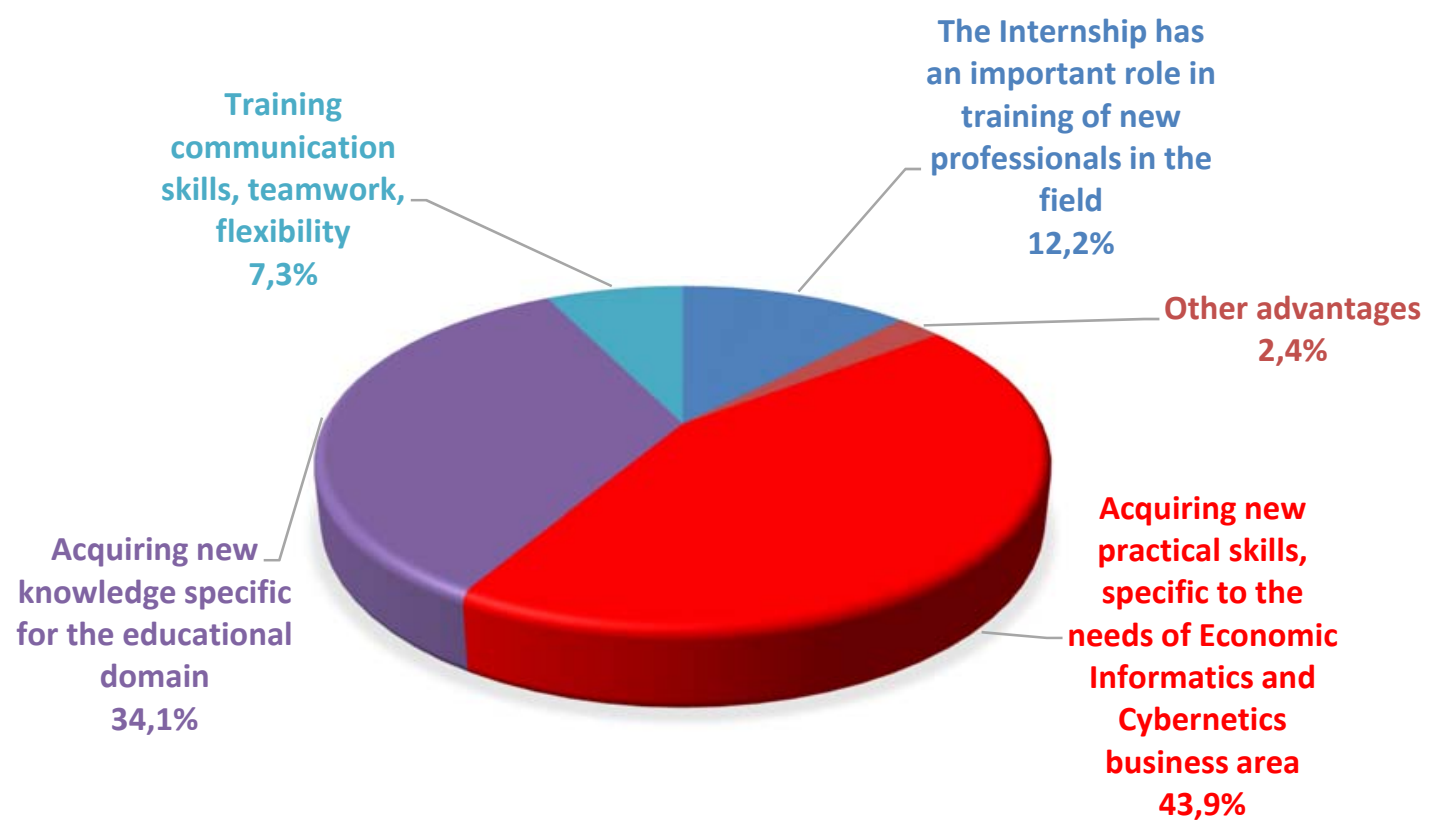

Fig. 1. Expected benefits of the target group about InfoStart internship program

Another question aimed to identify the students' requirements referring the internship project. Based on the average marks (from a 10 scale) awarded by the students from the target group, the most important requirements, which obtained 8.6 average points are to benefit by adequate working conditions, during the Internship, and the activity of the trainer, from the company, responsible to direct the students' work. Also of high importance, earning 8.5 average points is the necessity of connecting theoretical concepts with practical applications. Figure 2 presents all requirements expressed by students. 
to benefit by adequate working conditions, during the Internship

activity of the trainer from the company responsible to direct the students' work

to be explained the links between theory and the practical elements encountered;

to be monitored and to receive feedback during practice;

the content curriculum to be dense and complex;

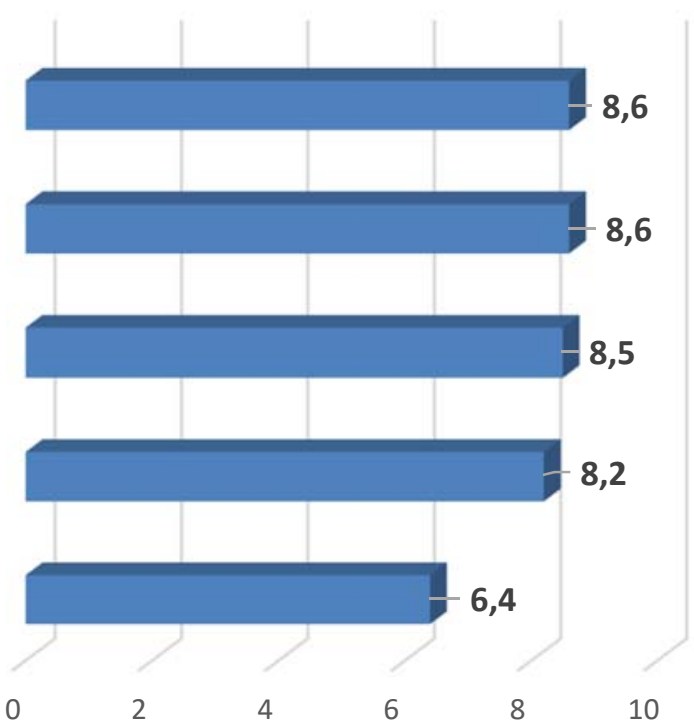

10

Fig. 2. Students' requirements regarding InfoStart internship program

Another question refers to the expected results, concerning the internship program. The results are presented in figure 3 . The fact that the students will have the chance to realize what skills and competencies they need to develop to increase their potential to be employees is considered to be the most important result of the internship program, achieving 4.4 points, from 5. Another important result expected, by the target group, getting 4.1 points from 5 , is the fact that they will have the opportunity to meet professionals, which could facilitate employment in a good company. On the same importance is the opportunity to understand if the specific field of activity is appropriate for students.

To have the chance to realize what skills I need to develop to increase my potential to be employed on a desired position;

To have the opportunity to meet professionals which could facilitate employment in the company;

Let me understand if I want to work in this field of activity in which the company operates;

I will be able to understand the utility of theoretical knowledge accumulated during academic courses;

I could create new connections that will help me to get a new job;

I'll be able to see to the schedule of a working day (from the position of the employee);

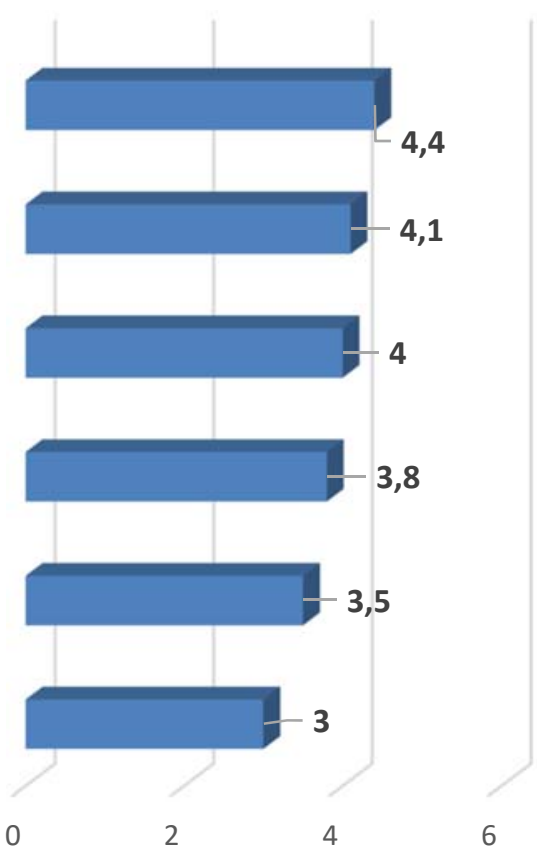

Fig. 3. The expected results of InfoStart internship program 
3 Students' Assessments after Completion the Internship Program

At the end of the internship program developed within InfoStart project, each participating students completed a self-evaluation reports. So 397 fulfilled self-evaluation reports have been achieved.

This study adopted an in-depth quantitative research, so it is fully representative, for the target population. The self-evaluation report includes a section referring to students' activity during internship, and a section with questions aiming to investigate the students' opinion about the InfoStart internship program. In order to compare the InfoStart program results with the target group expectation, in this paper we investigate only the students' opinion about the internship program organized within InfoStart program.
In order to investigate the quality of internship program, a 5-steps scale question has been used: "How do you rate, on a scale from 1 to 5 , the quality of the internship program: working conditions, projects in which you were involved, how have you been integrated within the company?"

The average score of this question is 4.6 points from 5 points. $68.2 \%$ of respondents evaluated the quality of the internship program with a maximum score, and $24.3 \%$ of respondents evaluate with 4 points from 5 , the quality of the internship program. Only $6.4 \%$ of respondents evaluate with 3 and 2 points the utility of the internship program, and $1 \%$ of respondents didn't answer to this question.

Table 1. Students' positive assessments about the quality of InfoStart internship program

\begin{tabular}{|l|c|}
\hline & Percentage \\
\hline Pleasant working environment; friendly employees of the host company & 31.4 \\
\hline $\begin{array}{l}\text { Good working conditions: available infrastructure, convenient working } \\
\text { program }\end{array}$ & 20.8 \\
\hline The trainer, from the employer, was always near us; proficient trainer & 13.2 \\
\hline I learned new useful technologies & 6.4 \\
\hline $\begin{array}{l}\text { Ability to work with real projects, or with projects simulating well real } \\
\text { projects }\end{array}$ & 4.5 \\
\hline Involvement in interesting projects & 4.5 \\
\hline Useful and understandable training courses were organized & 2.7 \\
\hline I learned to work in a team / to value the teamwork & 1.1 \\
\hline I was treated with respect, I have been integrated in the company team & 0.9 \\
\hline I had the opportunity to work through all stages of project development & 0.9 \\
\hline It allowed the improvement of communication skills, I made new friends & 0.8 \\
\hline $\begin{array}{l}\text { The Internship gave me more confidence in myself, and in my own } \\
\text { strength to turn in such a field. }\end{array}$ & 0.6 \\
\hline $\begin{array}{l}\text { It helped me to deepen / apply knowledge learned during the faculty clas- } \\
\text { ses }\end{array}$ & 0.5 \\
\hline I received proposal for the employment / further collaboration & 0.2 \\
\hline I learned that I have to look for answers to the encountered problems & 0.2 \\
\hline The activities were demanding & 0.1 \\
\hline The duration of the internship stage was not enough & 0.1 \\
\hline \multicolumn{1}{|c|}{ Total } & $\mathbf{8 9 . 1}$ \\
\hline
\end{tabular}


The students have to motivate the evaluation awarded, by using free assessments. 888 motivations have been provided, by 397 respond- ents. $89.1 \%$ of received reasons are appreciative assessments, as presented in table 1. $10.9 \%$ of reasons are rather negative assessments, and are figured in table 2.

Table 2. Students' negative assessments about the quality of InfoStart internship program

\begin{tabular}{|l|c|}
\hline & $\begin{array}{c}\text { Percent- } \\
\text { age }\end{array}$ \\
\hline I haven't worked / I haven't saw how it works real projects & 2.1 \\
\hline $\begin{array}{l}\text { There was no interaction with company employees, or the interaction was in- } \\
\text { appropriate }\end{array}$ & 1.5 \\
\hline $\begin{array}{l}\text { The activities developed during internship program have not folded well, on } \\
\text { the academic knowledge }\end{array}$ & 1.1 \\
\hline I have not been integrated into the company & 1.1 \\
\hline Insufficient technical equipment & 1.0 \\
\hline The projects that I worked on, I thought were very difficult & 0.9 \\
\hline Projects in which I was involved did not correspond with my specialization & 0.8 \\
\hline $\begin{array}{l}\text { I have been involved in complex projects / group / their activity was below ex- } \\
\text { pectations }\end{array}$ & 0.8 \\
\hline $\begin{array}{l}\text { I would have wanted more transparency, on the daily activities company em- } \\
\text { ployees are involved }\end{array}$ & 0.5 \\
\hline The distance to long, until the company centre & 0.3 \\
\hline I have not received my understandable explanations / inappropriate trainers & 0.3 \\
\hline $\begin{array}{l}\text { I expect to use in practice programming languages learned, in the university } \\
\text { and I didn't use them }\end{array}$ & 0.2 \\
\hline Inadequate working conditions & 0.1 \\
\hline There was no synchronization between faculty (tutors) and the company & 0.1 \\
\hline $\begin{array}{l}\text { There were too many theoretical discussions, I would like to have more practi- } \\
\text { cal applications }\end{array}$ & 0.1 \\
\hline & $\mathbf{1 0 . 9}$ \\
\hline
\end{tabular}

Another question from the same section is: "How do you rate, on a scale from 1 to 5 , the usefulness of internship program, for a future career?" The average score of this assessment is 4.5 points, from a maximum of 5 points. $68.5 \%$ of respondents rated the usefulness of internship program with the maximum score: 5 points, and $16 \%$ of respondents rated it with 4 points. The rest of $15.5 \%$ are non-answers and assessments of 1,2 and 3 .

Students' have to motivate their assessments referring to usefulness of internship program. The most frequent reasons expressed by students are: "I have accumulated some experience, which can be used successfully in the future"; "I realized once again that the profession that I chose is one suited for me"; "I found a job / a further collaboration"; "I learned to work in a team, in a real project"; "I acquired new knowledge, in the professional field"; "I have obtained certification, which I think will help me in the future"; "I learned to work with new IT technologies"; "I learned to tackle various problems encountered", and "The internship helped me better understand the requirements of the labor market".

Students' behavior during internship stage has been evaluate through the question: "How do you rate, on a scale from 1 to 5 , your behavior during the internship: your punctuality, presence, involvement, teamwork, initiative?" Again, the average score is very high, 4.7 points from 5 . More than a half of the respondents, $68.2 \%$, rated with maximum, 5 points, 
their behavior, during the internship stage. Almost $30 \%$ of respondents rated with 4 points their behavior. Only $2.1 \%$ of respondents give no answer or evaluate with 3 their behavior during the internship stage.

Students have to motivate their assessments referring to their own behavior, during InfoStart internship program. The most frequent reasons expressed by students are: "I think I totally involved in the successful completion of this internship because I really liked what I did"; "I have followed the work program"; "I have always worked with colleagues, to solve specific group tasks" ; "I like to be punctual, and I never missed to create a good impression" ; "The environment in which we worked was very competitive, and therefore I am always motivated to have initiative and to find creative and effective solutions", "I think I treated with seriousness and responsibility this internship"; "I managed to respect all daily tasks and I carried out the project on time"; "I took no initiative, in fact, no team has taken initiatives".

To evaluate the behavior of employees from the partner companies, the question "How do you rate, on a scale from 1 to 5 , the behavior of company employees that have worked with you, in the internship program: availability of collaboration, willingness to answer your questions, stimulate active participation in practice, communicativeness?" has been included in the self-evaluation report. The average score awarded by the students is the highest from this section, 4.8 points from 5 , proving an impeccable behavior of partner companies of InfoStart internship program. Moreover, $84.5 \%$ of respondents rated with the maximum, 5 points, the behavior of employees from partner companies, and $13.2 \%$ rated with 4 points, this behavior.

Students have to motivate their assessments referring to employees' behavior, during the internship program. The most frequent reasons expressed by students are: "Our employees were friendly, and willing to answer questions and help me when I was in trouble"; "Our employees were very open and patient"; "There were no person from IT department, to stimulate our active participation"; "Our employees are close to our age and we got along very well" and "The staff was like family to me".

Figure 4 includes an overall evaluation of the entire InfoStart project, based on students' assessment after completing the internship stage, reveal very good results. 


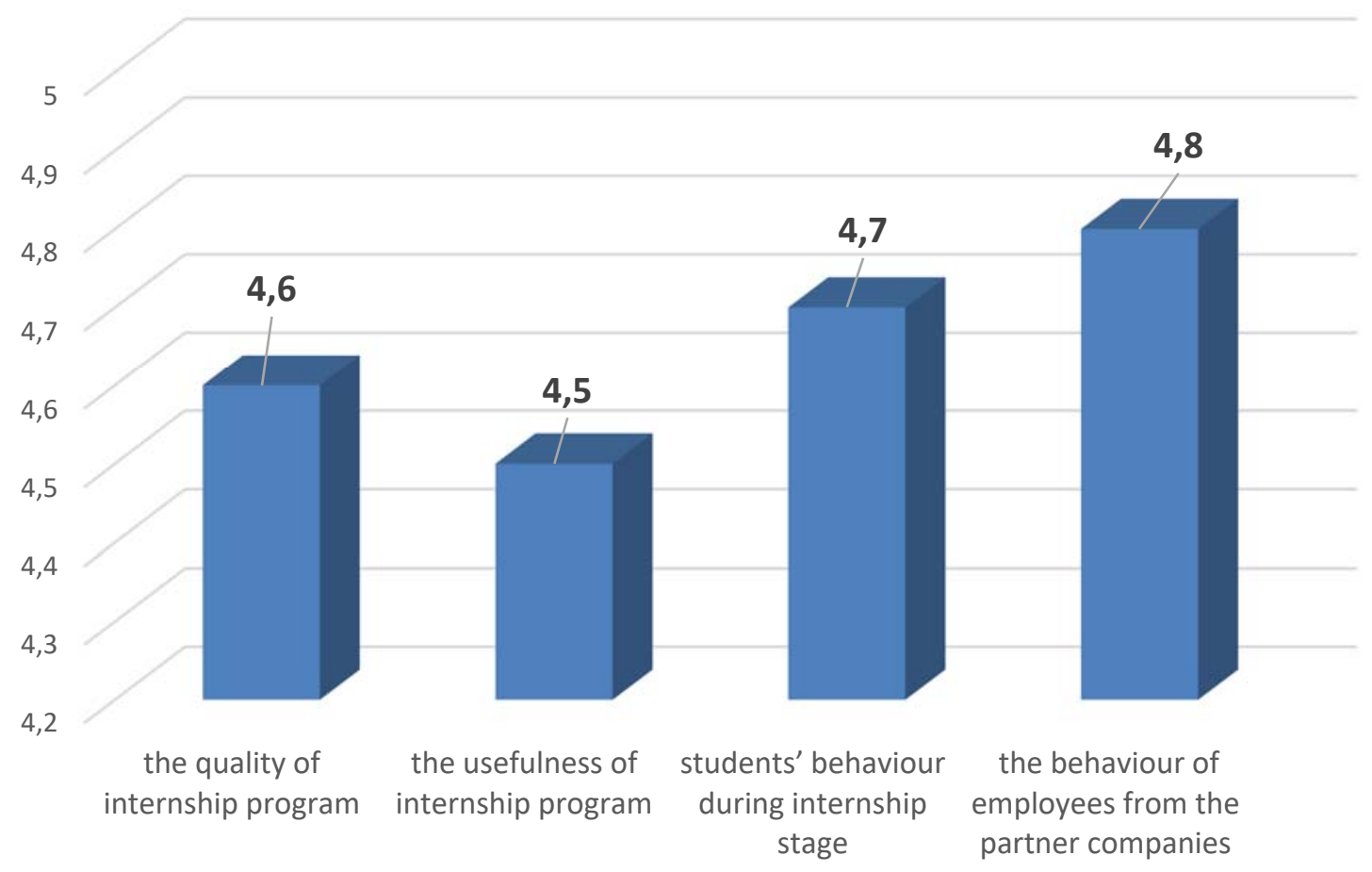

Fig. 4. The overall evaluation of InfoStart internship program

\section{Conclusions}

By comparing students' expectations express prior to the internship stage, with the students' assessments after completed the internship stage, we can conclude that expectations formulated by the students prior to internship stage, were met and exceeded during internship stage organized by InfoStart program, from all points of evaluation.

Students' assessments reveals a very successful internship program in Economic Informatics and Cybernetics, and helped to find issues aiming to be improved by the future internship programs, in this field.

\section{Acknowledgment}

This work was supported by the "InfoStart The beginning of your career in IT", financed by the European Social Fund Operational Programme for Human Resources Development 2007 - 2013, POSDRU/161/2.1/G /138408.

\section{References}

[1] Anderson, W., Cohen, M., Hogan, S., \& Holzman, S. Karr, E. (2012), Science librarian internship as a way to get started in eScience. Journal of eScinece Librarianship, 1(1), 36-40.

[2] Chan L.J., Hung W.H. (2015), Evaluation of an Online Internship Journal System for Interns, Procedia - Social and Behavioral Sciences 191, pp. $1024-1027$.

[3] Fox, T. (2001), A sense of place. Caterer and Hotelkeeper 189 (4160).

[4] Kandampully, J., Mok, C., Sparks, B. (2001), Service quality management in hospitality, tourism, and leisure. Haworth Hospitality Press, New York.

[5] Tobias, A.J. (1996), Internships, coop experience provide an edge. Electronic Engineering Times 921, c4-c6. 


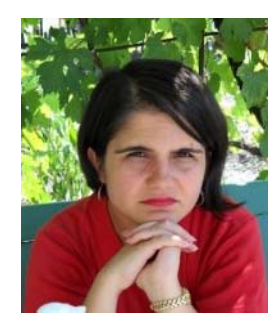

Adriana REVEIU has graduated the Faculty of Cybernetics, Statistics and Economic Informatics. She holds a PhD diploma in Economic Cybernetics and Statistics. She is associate professor in Economic Informatics field and branches within Department of Economic and Informatics and Cybernetics at Faculty of Cybernetics, Statistics and Economic Informatics from Bucharest University of Economic Studies. She is the author and co-author of 10 books and over 50 articles in journal and proceedings of national and international conferences, symposiums, workshops in the fields of regional development, data management, multimedia and learning systems.

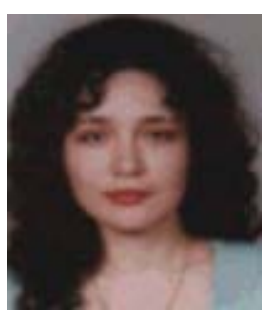

Ana-Ramona BOLOGA (born in 1976) is associate professor at the Bucharest University of Economic Science from Bucharest, Economic Informatics and Cybernetics Department. Her PhD paper was entitled "Software Agents Technology in Business Environment". Her fields of interest are: integrated information systems, information system analysis and design methodologies, and software agents. 